phys. stat. sol. (b) $\underline{54}, \mathrm{~K} 81$ (1972)

Subject classification: 13.4 and $20.1 ; 22.5 .2$

Max-Planck-Institut für Festkörperforschung, Stuttgart (a), and Physikalisches Institut der Universität Würzburg (b)

\title{
Impurity-Pair Mode in NaCl:KF
}

\section{By}

M. ISHIGA MA (a), C.R. BECKER (b), T.P. MARTIN (a), and W. PRETTL (a)

Impurity pair absorption is, in general, difficult to observe above the isolated impurity absorption background. However; if the impurity pairs give rise to resonant modes, observation is simplified. Resonant pair modes have been reported in $\mathrm{NaCl}: \mathrm{Ag}(1), \mathrm{KCl}: \mathrm{Na}(2,3)$, and $\mathrm{NaCl}: \mathrm{F}(4)$. In this note, we report the observation of an infrared absorption line due to a $\mathrm{KF}$ impurity pair in $\mathrm{NaCl}$.

The $\mathrm{NaCl}$ crystals used in this experiment were grown in air by the Czochralski technique. The concentration of fluorine in the crystals was determined absolutely using a specific ion electrode method in which aqueous solutions prepared from the infrared samples were compared with solutions containing known concentrations of fluorine ions. The concentration of the potassium impurities was determined by flame spectroscopy. The transmission of the crystals was measured at $7^{\circ} \mathrm{K}$ using a RIIC Michelson interferometer.

For $\mathrm{NaCl}$ samples with a high concentration of both fluorine and potassium impurities, a $1.5 \mathrm{~cm}^{-1}$ wide absorption line was observed at $16.5 \mathrm{~cm}^{-1}$. This line was not present in samples with a high concentration of only fluorine or only potassium. A more careful analysis indicated that the strength of the absorption line was linearly proportional to the product of the concentration of the fluorine impurity times the concentration of the potassium impurity, Table 1. This indicates that the resonance mode is due to a KF impurity pair.

An isolated fluorine impurity in $\mathrm{NaCl}$ has a triply degenerate resonance absorptior. line at $59.5 \mathrm{~cm}^{-1}(5)$. If a relatively large potassium ion replaces one the neighbouring sodium ions, this line should split into a high frequency, non-degenerate line corresponding to atomic motion along the axis of the pair configuration and into a low frequency, doubly degenerate line. Apparently, we have observed this doubly degenerate line. The non-degenerate line was not observed. This is not surprising 
physica status solidi (b) 54

Table 1

Pair mode resonance absorption in $\mathrm{NaCl}: \mathrm{KF}$

\begin{tabular}{|c|c|c|c|c|}
\hline sample & $\begin{array}{c}\text { fluorine } \\
\text { concentration } \\
(\mathrm{mol} \%)\end{array}$ & $\begin{array}{c}\text { potassium } \\
\text { concentration } \\
(\mathrm{mol} \%)\end{array}$ & $\begin{array}{c}\text { product } \\
\text { concentration }\end{array}$ & $\begin{array}{c}\text { integrated } \\
\text { absorption } \\
\left(\mathrm{cm}^{-2}\right)\end{array}$ \\
\hline I & $\begin{array}{l}1.48+10 \% \\
\text { II }\end{array}$ & $0.18+10 \%$ & $0.27 \pm 20 \%$ & $2.0+20 \%$ \\
III & 1.01 & 0.21 & 0.13 & 1.4 \\
IV & 1.26 & 0.10 & 0.10 & 1.1 \\
V & 4.10 & 0.30 & 0.38 & 2.8 \\
VI & 0 & 0.96 & 0 & 0 \\
\hline
\end{tabular}

*) Product of column two and three.

since resonant mode absorption at frequencies appreciably higher than $60 \mathrm{~cm}^{-1}$ is not expected due to the high densitiy of states. Two mechanisms tend to lower the characteristic frequency of fluorine ion vibrations perpendicular to the impurity pair axis. The potassium impurity deforms the lattice so that the fluorine impurity has more room to move in directions perpendicular to the impurity pair axis. At the same time, the potassium impurity extends its own charge distribution toward the centre of the cavity tending to raise the bottom of the potential well in which the fluorine sits.

The authors would like to thank Dipl-Phys. Schuhmacher and Dipl.-Phys. Bittermann for valuable assistance in sample preparation.

\section{$\underline{\text { References }}$}

(1) W. MÜLlER, R. KAISER, and H. BILZ, Phys. Letters (Netherlands) 32A, 171 (1970).

(2) T.L. TEMPLETON and B.P. CLAYMAN, Solid State Commun. 9, 697 (1971).

(3) T.L. TEMPLETON and B.P. CLAYMAN, to be published in Phys. Rev.

(4) C.R. BECKER and T.P. MARTIN, Phys. Rev. B5, 1604 (1972).

(5) H.F. MACDONALD, M.V. KLEIN, and T.P. MARTIN, Phys. Rev. 177, 1292 (1969). 